http://jmscr.igmpublication.org/home/ ISSN (e)-2347-176x ISSN (p) 2455-0450

crossref DOI: https://dx.doi.org/10.18535/jmscr/v8i9.06

\title{
Solitary Nodule of the Third Toe: Sub Ungual Exostosis
}

Authors

\section{Dilbag Singh $^{1}$, Arvind Bhatia ${ }^{2}$, Rohit Kumar ${ }^{2}$, Ritu Rawat $^{3}$, Vandna Raghuvanshi ${ }^{4}$}

${ }^{1}$ Senior Resident, Dermatology, Pt. JLNGMC, Chamba, H.P., India

${ }^{2}$ M.O. Specialist, General Surgery, Pt. JLNGMC, Chamba, H.P., India

${ }^{3}$ Assistant Professor, Dermatology, Pt. JLNGMC, Chamba, H.P., India

${ }^{4}$ Assistant Professor, Radiodiagnosis, Pt. JLNGMC, Chamba, H.P., India

*Corresponding Author

\section{Rohit Kumar}

Department of General Surgery, Pt. JLNGMC Chamba (H.P.), Pin code 176310, India

\begin{abstract}
Subungual exostosis is a relatively uncommon, osteocartilaginous tumor affecting the distal phalanx of the toes or fingers. Though great toe is commonly involved, but can be seen on the lesser toes and even on the fingers. It's exact pathogenesis remains unknown. Surgical excision remains the mainstay of treatment with a success rate of $>90 \%$. We report a rare case of subungual exostosis situated on the third toe in an adult female.
\end{abstract}

Keywords: Foot, subungual exostosis, nodule, tumour, toe.

\section{Introduction}

Subungual exostosis is a relatively uncommon, osteocartilaginous tumor affecting the distal phalanx of the toes or fingers ${ }^{1}$. In 1817, Dupuytren first described it as a bony growth of the distal phalanx of the great toe and was termed as "Dupuytren's exostosis. "[1] Feet are commonly involved than the hands. In foot, the great toe is most common to be involved. ${ }^{[2]}$ It's exact pathogenesis remains unknown. Various causes have been reported in the literature. Infection and trauma are considered the main contributing factors. ${ }^{[3]}$ Surgical excision remains the mainstay of treatment with a success rate of $>90 \% .{ }^{[4]}$ Here, we report a case of subungual exostosis in an adult female involving the third toe.

\section{Case Report}

A 20 year old female presented to our Dermatology OPD with the complaint of a tender, slow growing, well defined nodule on the third toe of the left foot for the last six months. On examination, it was $1 \mathrm{~cm} \times 1 \mathrm{~cm}$ in size, bony hard in consistency. Overlying skin at the centre of the nodule was thick, hyperkeratotic (figure 1).

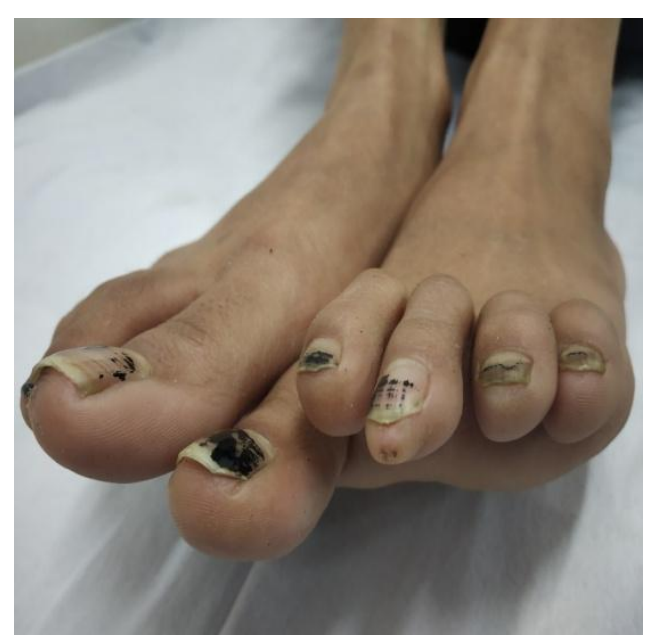

Figure 1: Nodule on the tip of third toe 
Nail plate of the affected toe was normal. Patient denied history of preceding trauma or infection. Due to the bony hard consistency of the nodule, patient was sent for the radiological examination. $\mathrm{X}$-ray of the foot taken in antero-posterior and oblique views showed an outgrowth of trabeculated bone projecting from the distal phalanx of the toe (Figure 2).

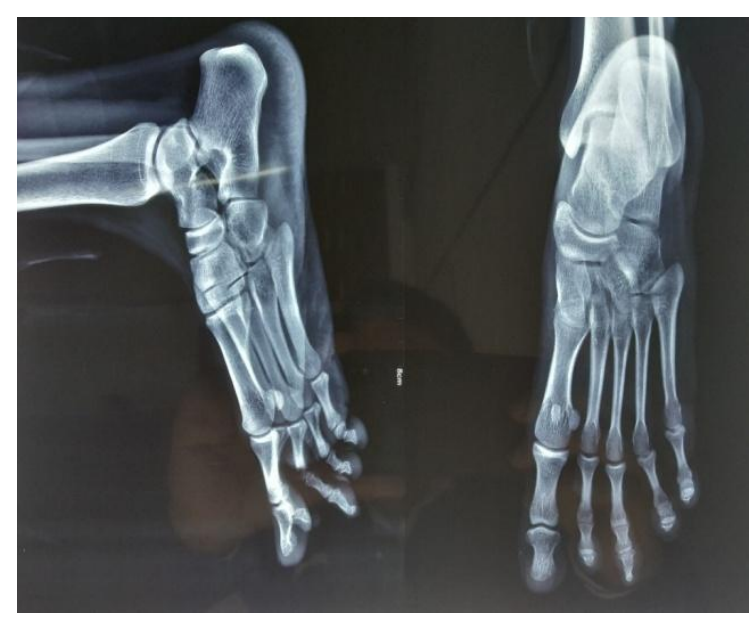

Figure 2: Outgrowth from the distal phalanx of third toe

There were no changes in the surrounding soft tissue and the distal phalanx. Radiological changes were consistent with the subungual exostosis. It was surgically excised and sent for the histopathology which showed trabeculae of metaplastic bone with overlying epidermis. No cartilage cap was seen. There was no evidence of granuloma or malignancy.

\section{Discussion}

Subungual exostosis is a rare osteocartilagenous tumour, arising in the distal phalanx of the digit, beneath or adjoining to the nail plate. It is considered as a rare variant of osteochondroma. ${ }^{[5]}$ It is more common in females and in the adolescent age group. ${ }^{[4]}$ Though great toe is commonly involved, but can be seen on the lesser toes and even on the fingers. ${ }^{[6]}$ Our case shows the involvement of the third toe with a delayed onset of the lesion.

Exact cause of the subungual exostosis is not known. Various factors suggested include trauma, tumour, chronic infection, hereditary abnormality or the activation of cartilaginous rest. Recently, a recurrent chromosomal translocation $\mathrm{t}(\mathrm{X} ; 6)(\mathrm{q} 24-\mathrm{q} 26 ; \mathrm{q} 15-21)$ has been identified suggesting the exostosis to be a neoplastic lesion. ${ }^{[2]}$

Clinically, it presents as pain over the nail or as a small firm mass protruding from the nail bed. ${ }^{[4]}$ Pain is exacerbated on activity, even the trauma due to wearing shoes can exacerbate the pain. ${ }^{[5]}$ There can be ulceration and infection of the nail bed. As the size of mass increases, overlying nail plate separates from the nail bed leading to fibrous tissue formation on its surface. ${ }^{[3]}$

Various differential diagnosis include subungual verruca, granuloma pyogenicum, glomus tumor, carcinoma of the nail bed, melanotic whitlow, keratoacanthoma, subungual epidermoid inclusions, enchondroma, Köenen's tumor, keratocanthoma and in growing toe nail. ${ }^{[6]}$

Main diagnostic tool is the $\mathrm{X}$ Rays. Plain radiographs reveal a trabecular bony outgrowth with well defined cortical margins without destruction of the parent bone. Radiolucent cartilaginous cap is not seen on radiographs.

Histopathological examination shows mature trabecular bone covered by a fibro cartilage cap with enchondral ossification from base to cap. ${ }^{[2]}$ Therefore, immature lesions show thick cartilage cap, while mature lesions shows thinned out cartilage cap because of replacement of cartilage by the trabecular bone. ${ }^{[5]}$ This can explain the absence of cartilage cap on histopathology in our case. Dermoscopy can also be used for the diagnosis of subungual exostosis which shows features like vascular ectasia, hyperkeratosis, onycholysis and ulceration. ${ }^{\text {[7] }}$

Mainstay of the treatment is excision followed by the curettage of the base to prevent the recurrences. $^{[6]}$

We report a rare case of subungual exostosis situated on the third toe in an adult female. Main purpose of the report is to consider this relatively uncommon entity in the differentials of the toe tip pathologies. Thereby, considering early radiographic assessment to prevent the delay in the diagnosis and management. 
Acknowledgement: NIL

\section{References}

1. Da Cambra MP, Gupta SK, Ferri-de-Barros F. Subungual exostosis of the toes: a systematic review. Clinical Orthopaedics and Related Research®. 2014 Apr 1; 472 (4):1251-9.

2. Gupta S, Mittal A, Gupta S, Mahendra A, Dhull AK. Subungual exostosis of the thumb-first case report in youngest age. Indian J Dermatol. 2009 Jan 1;54(5):46.

3. Malkoc M, Korkmaz O, Keskinbora M, Seker A, Oltulu I, Bulbul AM, Say F, Cakir A. Surgical treatment of nail bed subungual exostosis. Singapore medical journal. 2016 Nov;57(11):630.

4. Başar H, Inanmaz ME, Başar B, Bal E, Köse KÇ. Protruded and nonprotruded subungual exostosis: differences in surgical approach. Indian journal of orthopaedics. $2014 \mathrm{Jan} ; 48$ (1):49.

5. Ilyas W, Geskin L, Joseph AK, Seraly MP. Subungual exostosis of the third toe. Journal of the American Academy of Dermatology. 2001 Dec 1;45(6):S200-1.

6. Aggarwal K, Gupta S, Jain VK, Mital A, Gupta S. Subungual exostosis. Indian J of Dermatol, Venereol and Leprol. 2008 Mar 1;74(2):173.

7. Tchernev G, Grigorov $\mathrm{Y}$, Philipov S, Chokoeva A, Wollina U, Lotti T, Cardoso J, Yungareva I, Lozev I, Maximov GK. Subungual exostosis in a young soccer player. Open access Macedonian journal of medical sciences. 2018 Jan 25;6(1):52. 